\title{
El tratamiento jurisprudencial de la controversia sobre la reelección en Santiago del Estero
}

\author{
The jurisprudential treatment of the controversy \\ over reelection in Santiago del Estero \\ O tratamento jurisprudencial da polêmica sobre a \\ reeleição em Santiago del Estero
}

Le traitement jurisprudentiel de la controverse sur la réélection à Santiago del Estero

圣地亚哥德尔埃斯特罗(Santiago del Estero)关于改选争 议的法理学处理

\author{
Miguel Agustín Torres ${ }^{1}$ \\ Universidad Nacional de Tucumán - Argentina
}

Revista Derechos en Acción ISSN 2525-1678/ e-ISSN 2525-1686

Año 5/Nº 17 Primavera 2020 (21 septiembre a 20 diciembre), 380-415

DOl: https://doi.org/10.24215/25251678e464

Recibido: 01/09/2020

Aprobado: 15/09/2020

Resumen: Por sus diferentes implicancias, la reelección de las autoridades ejecutivas provinciales es un tema que ha despertado un marcado interés entre los analistas especializados, generando variados aportes que atraviesan las distintas disciplinas que componen el amplio campo de las ciencias sociales. Focalizándose en la dimensión jurídica de la cuestión, en este trabajo se procura caracterizar el tratamiento jurisprudencial que recibió la controversia suscitada, en el año 2013, en torno a

1 Abogado [UNT] y Doctor en Derecho [UBA]. Investigador del CONICET [CITCA - CONICET]. Docente de la Universidad Nacional de Catamarca [UNCa]. (ORCID: https://orcid.org/00000003-3410-1961). 
la reelección gubernamental en la provincia de Santiago del Estero. La indagación sobre el tema permite advertir las diferentes concepciones e interpretaciones referentes a la autonomía provincial, la soberanía popular y las instituciones y principios del orden republicano y representativo, que subyacieron a las decisiones sobre el asunto en el ámbito de la justicia provincial y de la Corte Suprema de Justicia de la Nación.

Palabras clave: Reelección gubernamental, Santiago del Estero, Controversia, Tratamiento Jurisprudencial

Abstract: Due to its different implications, the re-election of provincial executive authorities is a subject that has aroused significant interest among specialized analysts, generating various contributions that cross the different disciplines that make up the broad field of social sciences. Focusing on the legal dimension of the issue, this article tries to characterize the jurisprudential treatment that received the controversy that arose, in 2013, around the government reelection in the province of Santiago del Estero. The investigation on the subject allows us to notice the different conceptions and interpretations referring to provincial autonomy, popular sovereignty and the institutions and principles of the republican and representative order, which underlay the decisions on the matter in the sphere of provincial justice and the Supreme Court of Justice of the Nation.

Keywords: Government reelection - Santiago del Estero - Controversy Jurisprudential treatment

Resumo: Pelas suas diferentes implicações, a reeleição de autoridades executivas provinciais é um tema que tem suscitado marcado interesse entre analistas especializados, gerando diversos contributos que perpassam as diferentes disciplinas que constituem o amplo campo das ciências sociais. Enfocando a dimensão jurídica da questão, este trabalho busca caracterizar o tratamento jurisprudencial que recebeu a polêmica que surgiu, em 2013, em torno da reeleição governamental na província de Santiago del Estero. A investigação sobre o tema permite perceber as diferentes concepções e interpretações sobre a autonomia provincial, a soberania popular e as instituições e princípios da ordem republicana e representativa, que fundamentam as decisões sobre a matéria no âmbito da justiça provincial e do Supremo Tribunal de Justiça da Nação. 
Palavras-chave: Reeleição governamental, Santiago del Estero, Controvérsia, Tratamento Jurisprudencia

Résumé: En raison de ses différentes implications, la réélection des autorités exécutives provinciales est un sujet qui a suscité un intérêt marqué parmi les analystes spécialisés, générant diverses contributions qui traversent les différentes disciplines qui composent le vaste domaine des sciences sociales. Focalisé sur la dimension juridique de la question, cet ouvrage tente de caractériser le traitement jurisprudentiel qui a fait I'objet de la polémique née, en 2013, autour de la réélection du gouvernement dans la province de Santiago del Estero. L'enquête sur le sujet permet de constater les différentes conceptions et interprétations de l'autonomie provinciale, de la souveraineté populaire, des institutions et principes de l'ordre républicain et représentatif, qui sous-tendent les décisions en la matière dans le domaine de la justice provinciale et de la Cour suprême de justice de la nation.

Mot-clés: Réélection du gouvernement, Santiago del Estero, controverse, traitement juridictionnel

摘要：由于其不同的含义，连任省级行政机关这一话题引起了专业 分析师的浓厚兴趣, 产生了跨越社会科学广泛领域的不同学科的各 种贡献着眼于问题的法律层面这项工作试图描述法学治疗方法的 特征该法学治疗方法于2013年围绕圣地亚哥.埃斯特罗省政府的改 选而引起了争议通过对该问题的调查我们可以注意到有关省级自 治人民主权以及共和制和代议制的制度和原则的不同概念和解释 这些概念和解释奠定了省级司法和司法管辖权领域对此问题的决 定的基础国家最高法院

关键字: 政府改选, 圣地亚哥·德尔埃斯特罗 (Santiago del Estero), 争议, 法理学治疗

\section{Introducción}

La indagación sobre la reelección de las máximas autoridades ejecutivas en los ordenamientos provinciales provincial representa un tema significativo que ha motivado variadas aportaciones que, atravesando el vasto ámbito de las ciencias sociales, 
abordan distintos aspectos implicados en esta cuestión (Almaraz, 2010; Jolías y Reina, 2011; Cardarello, 2012; Liendo, 2014; Del Cogliano y Varetto, 2016; Altavilla, 2017; Gervasoni y Nazareno, 2017; Valenzuela y Medina, 2020). Enmarcado, precisamente, en la importancia que reviste el tópico, el examen de la controversia generada en torno a la reelección gubernamental de Santiago del Estero $^{2}$ del año 2013, adquiere, a su vez, una relevancia adicional, la cual puede ser apreciada tanto desde una perspectiva jurídica como desde un enfoque político-institucional.

Desde un plano jurídico puede sostenerse que el tema interesa puesto que permite conocer las diferentes interpretaciones, receptadas en la jurisprudencia generada en el ámbito judicial de la provincia de Santiago del Estero y en la decisión judicial de la Corte Suprema de Justicia de la Nación, sobre el instituto de la reelección y de las cláusulas constitucionales locales que la norman. Del mismo modo, porque posibilita distinguir las diversas concepciones sobre los mecanismos y vías de modificación de la carta política provincial, que subyacen a aquellos argumentos. Pero, principalmente, porque a través de la solución judicial sobre este asunto, el máximo tribunal nacional sentó un precedente para el tratamiento de cuestiones con un sustento empírico similar, y que efectivamente tuvo oportunidad de invocar a posteriori ${ }^{3}$.

2 La provincia posee su cuota de importancia en la historia nacional, especialmente en la etapa colonial en virtud de su aporte al desarrollo del incipiente proyecto urbano del noroeste, y, en menor medida, por su participación en el tramo inicial del trayecto de construcción del Estado argentino. Así, desde una perspectiva histórica, puede afirmarse que Santiago, al decir de Alen Lascano (1996) una auténtica ciudad imperial, representó el epicentro del noroeste colonial. Fundada en el año 1553, se convirtió en el primer núcleo urbano exitoso, ya que durante treinta años fue la única ciudad que no resultó destruida, despoblada o trasladada totalmente (Igareta, 2012). No obstante, su trascendencia para la época no sé circunscribe exclusivamente a su perdurabilidad, sino que ella radica, en buena medida, en su contribución para la conformación de otros asentamientos urbanos en la región, hasta avanzado el Siglo XVII, al suministrar recursos humanos y materiales a todas las expediciones destinadas a tales propósitos (Igareta, 2012). Justamente, por tal razón es conocida, tradicionalmente, como "Madre de Ciudades".

3 Ciertamente, la Corte Suprema de Justicia de la Nación invocó el criterio vertido en la disputa sobre la reelección en Santiago del estero, al resolver la cuestión problemática planteada con motivo de la reelección en la provincia de Río Negro. 
A su vez, desde un plano político-institucional, corresponde resaltar que la temática, también, reviste trascendencia, debido a que la discusión implicada en la cuestión de la reelección se desenvolvió en un escenario que, en las últimas décadas, albergó el desenvolvimiento de destacados procesos políticos. Así, las definiciones que, durante esos años, contribuyeron a describir la fisonomía política e institucional de la provincia, reflejaron, en algunos casos, tendencias que, en su momento, encontraron reproducción en diferentes espacios provinciales y, en otros supuestos, constituyeron expresiones peculiares de la dinámica política santiagueña. Justamente, puede afirmarse, al respecto, que su sistema electoral vigente, cuyo diseño e implementación deriva normativamente de la propia carta política provincial y del código electoral local, si bien no observa mayores diferencias técnicas con lo que acontece en otras provincias, se sitúa en el contexto de uno de los procesos políticos que particularizan, actualmente, a la realidad política de la provincia.

De esta manera, la experiencia institucional de Santiago del Estero de los últimos años ofrece un rasgo que, en términos comparativos, la singulariza. Su historia reciente se resume en el desenvolvimiento de dos figuras políticas que, a través del despliegue de sus respectivas estrategias para la concentración de poder en el marco de complejos fácticos disímiles, terminaron representando -y una de ellas aún lo sigue haciendo- dos instancias de hegemonía en la arena local. El devenir político de los últimos decenios alberga el tránsito desde el ocaso y desmoronamiento del "juarismo" hasta el surgimiento y consolidación del "zamorismo".

La intervención federal a la provincia del año 2004 comportó el desenlace definitivo de la prevalencia de Carlos Juárez (Dandan, 2010; Picco, 2013), cuyo proceder político y su estilo de gobierno estimularon diferentes esfuerzos de caracterización por parte de quienes se interesaron en los variados aspectos de este capítulo de la historia provincial ${ }^{4}$, condensado en la obra

4 Dargoltz, Gerez y Cao (2006) califican al ciclo juarista de 'regimen caudilllista'. Saltalamacchia y Silveti (2012), por su parte, acercan al juarismo a los regímenes de tipo 'clientelar'. 
política del caudillo justicialista. A partir del triunfo obtenido en las elecciones convocadas por la provisoria administración federal de la provincia para regularizar el ritmo institucional, comienza a configurarse el señorío político del "zamorismo" (Ortiz de Rozas, 2011). Mientras la preeminencia del juarismo se desarrolló con intermitencias, originadas en circunstancias de diferente naturaleza, a lo largo de una considerable proyección temporal que atravesó la segunda mitad del siglo pasado; el predominio de la elite dirigente encabezada por Gerardo Zamora no registró interferencias desde su acceso al poder, desenvolviéndose ininterrumpidamente desde entonces.

De modo semejante a lo sucedido con otras manifestaciones del accionar estatal, la evolución y el funcionamiento del régimen electoral no resultaron ajenos a estos procesos de edificación y sedimentación del poder político que tuvieron lugar en la provincia en los últimos decenios. Esto se puede apreciar, particularmente, al examinar el recorrido que describió la incorporación del mecanismo de la reelección. Las controversias y debates generados en torno a la determinación de la procedencia de la reelección en los comicios de 2013, lejos de circunscribirse a discrepancias de naturaleza técnica, terminaron reflejando las diferentes pretensiones de los principales actores políticos del ámbito provincial.

Sin prescindir, en el análisis, de la consideración que merece la incidencia ejercida por los factores procedentes del contexto político institucional en sentido estricto, en esta contribución nos focalizamos en la dimensión jurídica de la cuestión. Teniendo en cuenta ello, en este trabajo se procura caracterizar el tratamiento jurisprudencial que recibió la controversia suscitada, en el año 2013, en torno a la reelección gubernamental en la provincia de Santiago del Estero. En tal cometido efectuamos un examen del marco normativo referente al régimen electoral

A su vez, Farinetti y Zurita (2015) catalogan al juarismo como una forma de dominación consolidada en virtud de "la máquina electoral y el Estado, a través de la construcción de una multiplicidad de espacios de poder en la vida cotidiana" (Farinetti y Zurita, 2015, pág. 13). 
provincial y de los dispositivos constitucionales locales que insertan la reelección gubernamental en dicho sistema electoral; y, asimismo, realizamos un análisis de las piezas jurisprudenciales de la justicia provincial generadas sobre la cuestión y de la decisión de la Corte Suprema de Justicia de la Nación que dirimió el conflicto legal planteado.

Su desarrollo se estructura de la siguiente manera. En una sección inicial se describen algunos aspectos centrales del sistema electoral vigente en la provincia de Santiago del Estero. Luego se aborda la discusión normativa trabada sobre la reelección gubernamental en la provincia de Santiago del Estero, en el marco de la contienda electoral local del año 2013, a través de una sección distribuida en dos apartados que contemplan, sucesivamente, i) los antecedentes cercanos del proceso de recepción constitucional de la reelección en el orden provincial, y ii) los argumentos que fundamentan las diferentes interpretaciones recogidas en la producción jurisprudencial específica. Por último, a modo de cierre, se expresan una serie de comentarios finales sobre los tópicos analizados.

\section{El Sistema Electoral. Características Generales}

Las pautas que ordenan la configuración y el funcionamiento del actual sistema electoral santiagueño surgen de la Constitución Provincial reformada en el año 2005 y del Código Electoral local. Con sujeción a los lineamientos que en la materia establece la mencionada carta política de 2005, la ley 6908, de septiembre de 2008, instauró el denominado Código Electoral Provincial. Este cuerpo normativo específico recibió, a su vez, sucesivas actualizaciones a través de las leyes 6914 y 6921 , ambas de octubre de 2008, y de la ley 7102 de diciembre de 2012. Sancionado en el último año de la gestión del gobernador Zamora, este digesto electoral se implementó, por primera vez, en los comicios para renovar autoridades del Ejecutivo y del Legislativo del 30 de noviembre de 2008, instancia en al cual obtuvo la reelección el citado mandatario. 
El sistema electoral vigente se caracteriza, entre otras, por las siguientes notas:

- Los lineamientos principales del régimen electoral se encuentran contenidos en la Constitución Provincial del 2005. Aspectos como la aplicación del mecanismo proporcional de cobertura de los cargos correspondientes a los órganos colegiados, la conformación de un distrito electoral único, la prohibición del voto doble y simultáneo y la necesidad de contemplar legalmente el desenvolvimiento del proceso electoral encuentran recepción en la carta magna provincial. De esta manera, el artículo 44 del texto constitucional, luego de reconocer que el régimen electoral revestirá un carácter uniforme en toda la geografía provincial, enuncia las bases a las cuales se ajustará el despliegue del mismo:

1. El sistema electoral que regirá para la elección de los cuerpos colegiados se establecerá sobre la base de la representación proporcional. 2. El territorio provincial y municipal, según corresponda, se constituye en distrito único para todos los actos electorales. 3. Queda expresamente prohibido el sistema electoral de doble voto simultáneo y acumulativo. 4 . Todo proceso electoral puede ser fiscalizado por los partidos políticos intervinientes. 5. La autoridad comicial dispone de la fuerza pública a los efectos de asegurar la regularidad del acto. 6. Todos los electores gozan durante el acto comicial de inmunidad de arresto, salvo en el caso de flagrante delito o de orden escrita de autoridad competente. La ley que reglamentará el régimen electoral deberá ser sancionada por la mayoría absoluta de la totalidad de los miembros de la Cámara de Diputados (Const. Pcial. de Sgo. del Estero, 2005, art. 44).

- La elección del gobernador y el vicegobernador se concreta a través de la simple pluralidad de sufragio. En este proceso electoral, la totalidad del territorio provincial es considerado un distrito único. La duración del mandato de ambas autoridades del Poder Ejecutivo se fija en cuatro años, pudiendo 
ser reelectos por un solo término de idéntica duración. Esta limitación referente a la reelección opera también en el supuesto de sucesión recíproca entre la figura del gobernador y la del vicegobernador. Es decir, que tanto el gobernador o vicegobernador sólo pueden ser reelectos por un solo periodo, aún en el supuesto de que intercambien mutuamente sus cargos en la fórmula electoral. Por ende, tanto el gobernador como el vicegobernador, previamente reelectos, no pueden ser elegidos para cualquiera de los dos cargos sino cuando hubiera transcurrido el intervalo de un período (Cód. Elec. de Sgo. del Estero, 2008, art. 63). A los fines de la elección el territorio provincial en su totalidad es considerada un único distrito (Cód. Elec. de Sgo. del Estero, 2008, art. 63).

- Las situaciones de acefalia se encuentran previstas en la Constitución Provincial. Según la ley fundamental de la provincia, el vicegobernador es el reemplazante y sucesor natural del gobernador. La línea sucesoria institucional se integra por el vicepresidente primero o, en su defecto, por el vicepresidente segundo de la legislatura. Cuando la acefalia no fuese temporaria, alcanzara al gobernador y al vicegobernador y ocurriera cuando faltase más de dos años para concluir el período, la autoridad legislativa a cargo del Poder Ejecutivo (vicepresidente primero o, en su defecto vicepresidente segundo de la legislatura) convocará a la ciudadanía a nuevas elecciones, las cuales deberán llevarse a cabo dentro de los sesenta días de producida la acefalia.

Cuando esta misma situación aconteciera faltando menos de dos años para la terminación del período, la autoridad legislativa que desempeñara transitoriamente el Poder Ejecutivo convocará a la legislatura para que procediera a cubrir, los cargos vacantes de gobernador y vicegobernador, con dos de sus propios miembros elegidos a tal efecto en una única sesión. La designación de los dos legisladores que culminarán el mandato pendiente requiere, en un principio, de la obtención de la mayoría absoluta de votos dentro del cuerpo legislativo, en donde cada parlamentario tendrá un voto nominal. Si esta mayoría no se alcanzara, se 
reiterará la votación en la misma sesión. En caso empate, decidirá el presidente de la legislatura votando por segunda vez. Asimismo, se prevé que, en el supuesto de que no se hubiera proclamado al nuevo gobernador el día en que debiera cesar el saliente, el presidente del Superior Tribunal de Justicia ejercerá temporariamente el Poder Ejecutivo.

- Los diputados provinciales y los convencionales constituyentes son elegidos a través del sistema proporcional D'Hont, conformando el escenario provincial un distrito único. Las elecciones de los diputados se efectuarán cada cuatro años, resultando simultáneas con las de gobernador y vicegobernador. Los diputados ejercerán sus funciones durante cuatro años, pudiendo ser reelegidos, de forma consecutiva, por un solo período de la misma extensión. Por lo tanto, habiendo resultado previamente reelectos, podrán ser elegidos nuevamente recién cuando hubiera transcurrido el intervalo de un mandato.

- La implementación del sistema proporcional D'Hont se encuentra consagrada en el artículo 71, el cual determina que los cargos a cubrir se asignarán de conformidad con las siguientes pautas:

a) El total de los votos obtenidos por cada lista que haya alcanzado como mínimo el dos por ciento (2\%) de los votos válidamente emitidos, será dividido por uno (1), por dos (2), por tres (3) y así sucesivamente hasta llegar al número igual al de los cargos a cubrir; b) Los cocientes resultantes, con independencia de la lista de que provengan, serán ordenados de mayor a menor en número igual al de los cargos a cubrir; c) Si hubiere dos o más cocientes iguales se los ordenará en relación directa con el total de los votos obtenidos por las respectivas listas y si éstos hubieren logrado igual número de votos el ordenamiento resultará de un sorteo que a tal fin deberá practicar el Tribunal Electoral Provincial; d) A cada lista le corresponderá tantos cargos como veces sus cocientes figuren en el ordenamiento indicado en el inciso b) (Cód. Elec. de Sgo. del Estero, 2008, art. 71). 
- El sistema proporcional también resulta aplicable a la elección de Concejales Municipales. De conformidad con este sistema se adjudican las bancas correspondientes, tanto las titulares como las suplentes, en el marco de comicios en los cuales los concejales son elegidos en forma directa por el electorado de los circuitos que componen cada municipio, el cual es considerado, a los fines del acto electoral, como un distrito único (Cód. Elec. de Sgo. del Estero, 2008, art. 78, inc. b). Los intendentes, por su parte, son elegidos a simple pluralidad de sufragios de forma directa por los electores de cada municipio (Cód. Elec. de Sgo. del Estero, 2008, art. 78, inc. a). La elección de intendentes y concejales deben efectuarse en forma simultánea (Cód. Elec. de Sgo. del Estero, 2008, art. 78, inc. a) y, en su caso, también, pueden coincidir con los comicios para elegir a las autoridades del Ejecutivo provincial y a los diputados provinciales (Cód. Elec. de Sgo. del Estero, 2008, art. 78, inc. d).

- A su vez los comisionados municipales son elegidos de modo directo, a simple pluralidad de sufragios, por el electorado de sus jurisdicciones correspondientes (Cód. Elec. de Sgo. del Estero, 2008, art. 79, inc. a). Estos comicios deben celebrarse en forma simultánea con las elecciones para gobernador, vicegobernador y diputados provinciales (Cód. Elec. de Sgo. del Estero, 2008, art. 79, inc. d).

- El mandato de los intendentes, concejales, comisionados y secretarios de las comisiones municipales tendrá una duración de cuatro años (Cód. Elec. de Sgo. del Estero, 2008, art. 81). En armonía con lo normado, en este aspecto, para otros cargos electivos de la provincia, aquellos sólo pueden ser reelegidos por un solo período consecutivo (Cód. Elec. de Sgo. del Estero, 2008, art. 81). Habiendo resultado reelectos solo pueden ser elegidos nuevamente luego de haber transcurrido el intervalo de un período (Cód. Elec. de Sgo. del Estero, 2008, art. 81).

Este sistema se complementa con otros aspectos concernientes a la dinámica electoral que resultan necesarios para su funcionamiento $\mathrm{y}$, los cuales se encuentran igualmente 
institucionalizados en el ámbito provincial. Así, la conformación y operatividad de los partidos políticos ${ }^{5}$, el acceso gratuito de los mismos a determinados espacios de publicidad en medios televisivos o de radiodifusión ${ }^{6}$, el financiamiento de las campañas electorales dispone de cobertura normativa ${ }^{7}$. Del mismo, Santiago del Estero cuenta con regulación específica sobre "consulta popular"8 y constituye, además, uno de los circuitos provinciales que tempranamente legisló en materia de "voto electrónico"9.

\section{La recepción constitucional de la reelección. Discusiones sobre su implementación}

\section{III.a. Antecedentes recientes}

En el año 1986, el gobierno de Carlos Juárez promovió la reforma de la Constitución Provincial. La iniciativa santiagueña inauguró la etapa de revisiones de los textos constitucionales que empezarían a describir, por aquellos años, algunas administraciones provinciales (Castiglione, 2010). A través de la reforma se procuró actualizar el sentido de la carta política, incorporando las tendencias modernas del constitucionalismo de aquella época (Castiglione, 2010). Así, encontraron recepción en el nuevo texto los derechos a la libertad de pensamiento y de expresión (Const. Pcial. de Sgo. del Estero, 1986, art. 19), el derecho de réplica (Const. Pcial. de Sgo. del Estero, 1986, art. 20), diferentes garantías, la acción habeas corpus (Const. Pcial. de Sgo. del Estero, 1986, art. 38), la acción de amparo (Const. Pcial. de Sgo. del Estero, 1986, art. 38), determinadas normas sobre

\footnotetext{
5 Normado por Ley Orgánica de los Partidos Políticos № 5.562.

6 Regulado por Ley 6681 sobre Espacios Gratuitos en los Medios de Radiodifusión y Televisión.

7 Normado por Ley 6680 de Financiamiento de Campañas Electorales Provinciales.

8 Contemplada por Ley 6659 de Consulta Popular.

9 Regulado por Ley 6679 referente al Sistema de "Voto Electrónico".
} 
régimen social, económico y financiero (Const. Pcial. de Sgo. del Estero, 1986, arts. 63, 64, 65, 65, 66, 67, 68, 69), previsiones sobre los regímenes del agua (Const. Pcial. de Sgo. del Estero, 1986, arts. 59, 60, 61), forestal (Const. Pcial. de Sgo. del Estero, 1986, art. 62), de la salud (Const. Pcial. de Sgo. del Estero, 1986, art. 70, $71,72,73,74,75,76)$. Se reguló también en materia de familia (Const. Pcial. de Sgo. del Estero, 1986, art. 77), minoridad (Const. Pcial. de Sgo. del Estero, 1986, arts. 78, 79, 80), juventud (Const. Pcial. de Sgo. del Estero, 1986, art. 81), tercera edad (Const. Pcial. de Sgo. del Estero, 1986, art. 82), discapacitados (Const. Pcial. de Sgo. del Estero, 1986, art. 83).

La normación del sistema electoral se encontraba contemplada en la Sección III (Const. Pcial. de Sgo. del Estero, 1986, arts. $84,85,86,87,88,89,90,91,92,93,94,95)$. El texto constitucional incorporó la figura del vicegobernador. De este modo, el artículo 121 disponía que, simultáneamente, con la elección de gobernador se debiera elegir un vicegobernador por un periodo igual $^{10}$ (Const. Pcial. de Sgo. del Estero, 1986, art. 121). A su vez, el artículo 108 erigía al vicegobernador como presidente nato de la legislatura, correspondiéndole votar en caso de empate (Const. Pcial. de Sgo. del Estero, 1986, art. 108). Se incrementó el número mínimo de legisladores a 45 (Const. Pcial. de Sgo. del Estero, 1986, art. 96). Se creó el Tribunal Fiscal (Const. Pcial. de Sgo. del Estero, 1986, arts. 149, 150, 151) y el Consejo de la Magistratura (Const. Pcial. de Sgo. del Estero, 1986, art. 165 y 166). Se clasificó a los municipios en tres categorías (Const. Pcial. de Sgo. del Estero, 1986, art. 218) y se les reconoció independencia de acción con respecto a todo otro poder (Const. Pcial. de Sgo. del Estero, 1986, art. 216). De conformidad con cada categoría, se fijaba el número de sus concejales (Const. Pcial. de Sgo. del Estero, 1986, art. 220, inc. 2). Con el propósito de asegurarles a

10 Expresamente el art. 121 prescribía: “El Poder Ejecutivo será desempeñado por un ciudadano con el título de gobernador de la provincia. Simultáneamente con la elección de gobernador se elegirá un vicegobernador, por idéntico período" (Const. Pcial. de Sgo. del Estero, 1986, art. 121). 
los municipios cierta independencia con relación a la voluntad del gobernador de turno se les asignaban recursos mínimos (Const. Pcial. de Sgo. del Estero, 1986, art. 220, incs. 10 y 11).

Sin embargo, la inserción de la alternativa de la reelección constituyó el verdadero móvil que impulsó la reforma y que, en definitiva, no habría de concretarse. Indudablemente, la conformación de la convención constituyente, en la cual la oposición dispuso de mayoría, terminó enervando aquel propósito de la conducción juarista (Castiglione, 2010). De esta manera el artículo 123, situado dentro del Capítulo I (De Su Naturaleza y Duración) de la Sección II (Poder Ejecutivo), establecía expresamente que: "el gobernador y vicegobernador ejercerán sus funciones por el término de cuatro años sin que evento alguno pueda motivar su prórroga. No podrán ser reelegidos sino con intervalo de un período, ni sucederse recíprocamente" (Const. Pcial. de Sgo. del Estero, 1986, art. 123).

Debieron transcurrir más de diez años para que se incorporara la alternativa de la reelección a la Constitución Provincial. Esto se concretaría, durante la cuarta gobernación de Juárez, mediante la reforma constitucional del año 1997. Precisamente, la revisión de la Constitución de 1986 se encontraba inspirada por el propósito de modificar la mencionada cláusula constitucional que impedía la reelección, contenida en el citado precepto 123. La letra del artículo 139, en la Constitución modificada, disponía que "el gobernador y su vice pueden ser reelectos" (Const. Pcial. de Sgo. del Estero, 1997, art. 139). El artículo 141, por su parte, contenía un mecanismo de reemplazo funcional del vicegobernador. Establecía esta norma que, en caso de vacancia o acefalia del vicegobernador, le correspondía al Poder Ejecutivo proponer una terna de diputados, de la cual la legislatura, por simple mayoría de votos, debía elegir al reemplazante hasta la culminación del mandato ${ }^{11}$. Lo normado por esta última cláusula debía ser correlacionado con la redacción del artículo 137.

11 Constitución de la Provincia de Santiago del Estero del Año 1997, artículo 141. 
Este precepto, además de referirse a las máximas autoridades que componían el Poder Ejecutivo, también incluía una cláusula concerniente al rol del vicegobernador en la mecánica gubernativa, especialmente en lo atinente a interacción con el órgano legislativo. Así, el dispositivo prescribía que:

El vicegobernador, en tanto no reemplace al gobernador en el ejercicio del Poder Ejecutivo, tendrá dentro de éste funciones de Consejero y en ese carácter asistirá a los acuerdos de Ministros, reuniones de gabinete e integrará el Consejo Económico social. Podrá concurrir a las sesiones de la Cámara de Diputados, como vocero del Poder Ejecutivo en el tratamiento de los proyectos e iniciativas del mismo, con derecho a voz (Const. Pcial. de Sgo. del Estero, 1997, art. 137).

De esta manera, apartándose de un criterio clásico en el reparto de facultades institucionales, la norma dispensaba al vicegobernador de la función de presidir el órgano legislativo que, usualmente, se le atribuye en los textos constitucionales. En este punto puede apreciarse con nitidez las intenciones políticas que albergaba el Ejecutivo de aquel entonces, ya que la inserción constitucional de esta cláusula especial se había efectuado considerando una eventual candidatura, como vicegobernadora, de la esposa del caudillo provincial, lo que, en definitiva, habría de suceder en las elecciones del año 2003 (Castiglione, 2010). Con tal redacción, que implicaba que el vicegobernador no tuviera necesariamente que concurrir a la cámara de diputados para presidir las sesiones legislativas, el líder del justicialismo local procuraba sustraer a su mujer de las críticas y de la exposición que suponía, inevitablemente, el cumplimiento de tal tarea institucional (Castiglione, 2010).

Además, la reforma elevó a cincuenta el número de diputados, debiendo ser elegidos veintidós en distrito único mediante lista única y los veintiocho restantes de las diferentes circunscripciones electorales en las cuales debía desagregarse el territorio provincial (Const. Pcial. de Sgo. del Estero, 1997, art. 115). Como otra particularidad del texto constitucional, se 
intentaba contener las perjudiciales connotaciones económicas de la gestión de los interventores federales, al establecerse que los actos de los mismos debían revestir, exclusivamente, naturaleza administrativa, no pudiendo comprometer el patrimonio presente o futuro de la provincia ${ }^{12}$ (Const. Pcial. de Sgo. del Estero, 1997, art. 14). La reelección introducida por esta Ley Fundamental se estrenó en la elección de agosto de 1999, en la cual, Carlos Juárez resultó reelecto como gobernador, esta vez acompañado en la vice gobernación por su esposa ${ }^{13}$.

La intervención federal a la provincia ${ }^{14}$, que abarcó el periodo comprendido entre abril de 2004 y marzo de 2005, pretendió modificar el texto constitucional de 1997. Empero, esta iniciativa encontró resistencia en un sector del radicalismo local que terminó cuestionando judicialmente la constitucionalidad de la Ley 6667, sancionada por la intervención, que declaraba la necesidad de la reforma de la carta política y convocaba a la elección de convencionales a tal fin. Ciertamente, el senador radical José Luis Zavalía dedujo, en el año 2004, una acción de amparo contra el Estado Nacional y el Provincial con el propósito de que se declarara la ilegalidad, ilegitimidad e inconstitucionalidad de la mencionada Ley 6667, solicitando

\footnotetext{
12 Rezaba el artículo 14": "En caso de intervención del gobierno federal, los actos que su representante practique deberán ser exclusivamente administrativos. Serán válidos para la Provincia si hubieren sido realizados de acuerdo con lo previsto por esta Constitución y las leyes de la Provincia. Sus funciones deberán limitarse a garantizar la forma republicana de gobierno, repeler invasiones exteriores o sostener o restablecer las autoridades constituidas si hubiesen sido depuestas por la sedición o por invasión exterior. En ningún caso podrá comprometer el patrimonio presente o futuro de la Provincia. Los magistrados, funcionarios y empleados nombrados por la intervención federal cesan automáticamente al asumir las autoridades electas, salvo confirmación o nuevo nombramiento de éstas. Los sueldos, retribuciones, compensaciones, viáticos y demás adicionales del Interventor Federal, Ministros, Secretarios de Estado, Subsecretarios y funcionarios no escalafonados designados por aquél, no serán abonados con fondos provinciales". (Const. Pcial. de Sgo. del Estero, 1997, art. 14).

13 Tanto Carlos Juárez y su esposa Mercedes Aragonés renunciaron a sus respectivos cargos el 10 de diciembre de 2001. Tres días después ambos fueron declarados por la legislatura santiagueña "protectores ilustres de la provincia". El 19 de diciembre, también de ese año, Juárez asumió como senador nacional.
}

14 Declarada por el Congreso de la Nación mediante Ley 25.881 del 1 de abril de 2004. 
que, hasta tanto se dictara una sentencia que resolviera el fondo de la cuestión, se decretara una medida cautelar ordenando la suspensión de los comicios para la elección de convencionales, fijados para el 31 de octubre de 2004 (Hauser, 2004; Gómez Diez, 2006). Para fundamentar su pretensión, el senador radical expuso, en su pretensión, entre otros, los siguientes argumentos, referidos a la determinación del alcance de los poderes del interventor federal:

[...] Por más amplias que sean las potestades acordadas al funcionario designado, está inhabilitado para adoptar decisiones que desnaturalicen la esencia del federalismo y la autonomía provincial (...) no podría dictar normas que alterasen el cumplimiento del art. $5^{\circ}$ de la Constitución Nacional, ni desconocer el alcance del art. $7^{\circ}$, como tampoco podría modificar los límites provinciales sin la conformidad de los representantes legítimos del pueblo de la provincia, ni crear comisiones especiales, nuevas regiones o asumir compromisos internacionales (...) Tampoco está habilitado para ejercer la función preconstituyente o constituyente, por lo que el gobierno federal no puede, por su intermedio, declarar la necesidad de la reforma constitucional e imponer un nuevo texto porque estaría ejerciendo una potestad que no fue delegada por las provincias (art. 121, Constitución Nacional) (...) El interventor carece de facultades para disponer una reforma en tanto es la provincia la que, de conformidad con las previsiones contenidas en el art. 122 citado, se da sus propias instituciones y se rige por ellas (...) Nadie puede sostener "racionalmente" que el interventor federal es depositario del Poder Constituyente (...) Reconocer el ejercicio de las facultades que se pretenden es la antesala de la subversión del sistema federal y la partida de defunción de las autonomías provinciales (CSJN, 2004, 327:3852).

Habiendo arribado la cuestión a conocimiento de la Corte Suprema de Justicia de la Nación, el máximo tribunal se declaró competente entendiendo que la causa correspondía a su 
jurisdicción originaria en los términos del artículo 117 de la Constitución Nacional. El pronunciamiento sobre la competencia contiene una serie de considerandos de relevancia. Entre otros aspectos, la Corte razonó que:

[...] Es dable recordar que aceptar la radicación de estas actuaciones en esta instancia constitucional es la única forma de garantizarle al Estado provincial un juez imparcial, dado que su calidad y preexistencia a la Nación misma impide someterlo a los jueces federales (...) (CSJN, 2004, 327:3852).

La Corte terminó concediendo la cautelar solicitada por el senador Zavalía y, por lo tanto, ordenó suspender el llamado a elección de convencionales hasta tanto se dictara una sentencia definitiva, interpretando que:

De proseguirse el proceso de reforma constitucional ya iniciado con el ejercicio de las facultades preconstituyentes que el actor niega al interventor federal y dictarse una sentencia favorable a esa pretensión, o bien la decisión podría ser ineficaz frente a los actos ya cumplidos o bien éstos podrían quedar viciados de nulidad, con el consiguiente trastorno institucional que ello acarrearía y la inútil realización de importantes erogaciones; en cambio, si la sentencia fuese desfavorable, la temporaria suspensión de aquel proceso no implicaría ninguna consecuencia negativa (CSJN, 2004, 327:3852) .

En este fallo, en el cual la Corte reconoció que la cuestión se situaba en la órbita de su competencia originaria, también se remitió, de modo expreso, al debate parlamentario que acompañó la sanción de la ley 25881 que declaraba la intervención a la provincia. Así, la sentenció incorporó un fragmento en el cual se discutía sobre la conveniencia de conferirle al interventor federal, a través de la norma, la potestad de reformar la Constitución Provincial. Al respecto, resulta útil, por su utilidad técnica y también por su pertenencia al oficialismo nacional de aquel momento, reproducir los argumentos de la senadora 
Fernández de Kirchner, contenidos en el apartado 25 de los considerandos:

Como presidenta de la Comisión de Asuntos Constitucionales la primera cosa que se me ocurre decir es que no podríamos sancionar este proyecto de ley violando nosotros mismos la Constitución. ¿Cómo vamos a imponer la reforma de una Constitución provincial desde una ley nacional? Es imposible hacer eso, por cuanto en tal caso estaríamos sancionando una norma claramente violatoria de la organización federal del país. La reforma de constituciones provinciales debe hacerse a través de mecanismos que prevén las propias constituciones. Así que es imposible abordar esto, por lo menos en el marco de legalidad constitucional desde el Congreso de la Nación (...) "Desde el pacto fundacional de 1853 y luego de décadas de lucha, las provincias argentinas lograron que la Nación no pudiera introducirse en la organización de las provincias. Lo que deben garantizar es la administración de justicia y la educación como únicas demandas por parte de la nación para que se les garanticen sus autonomías. O sea, que nosotros le impongamos una reforma constitucional desde la Nación es profundamente violatorio de la Constitución Nacional y de los pactos fundantes de la Constitución de 1853 (CSJN, 2004, 327:3852).

En definitiva, el plazo de la intervención habría de culminar antes de que se dictara una sentencia definitiva, razón por lo cual la Corte declaró abstracta la cuestión. En tal sentido la Corté manifestó que:

Este proceso carece de objeto actual en la medida en que, al haber concluido la intervención federal que promovió la reforma constitucional impugnada, ha desparecido el presupuesto fáctico que dio lugar al agravio constitucional que sustentó la pretensión declarativa (...) a esta Corte le está vedado expedirse sobre planteos que devienen abstractos en tanto todo pronunciamiento resultaría inoficioso al no decidir un conflicto litigioso actual (CSJN, 2006, 329:1898). 


\section{III.b. La reelección en la reforma constitucional del 2005. La discusión sobre los alcances de la cláusula transitoria sexta}

La "Constitución Juarista" recién habría de reformarse en el año 2005, durante el gobierno de Gerardo Zamora. Ya bajo la vigencia de esta carta política, la implementación de la reelección se convirtió, otra vez, en un componente de controversia social y de tensión política e institucional con motivo de la elección para gobernador del año 2013. La polémica se suscitó debido a la intención del gobernador Zamora de competir en dicha contienda electoral, abriendo, con ello, la posibilidad de un tercer período gubernamental consecutivo (Behrend, 2013). El protagonista central de la realidad política santiagueña de los últimos años transitaba, por entonces, su segundo mandato al cual había accedido a través de la reelección en los comicios de 2009. La discusión política encontraba su sustento jurídico en las divergentes interpretaciones que deparaba la colisión entre dos normas de la Constitución de 2005. Los dispositivos en crisis conciernen, ambos, a la reelección de la autoridad ejecutiva. Sin embargo, mientras uno de ellos, el artículo 152, regula con carácter general lo atinente a la reelección del gobernador y vicegobernador, el otro, la cláusula transitoria sexta, por su parte, en directa vinculación con el precepto del 152, contempla, exclusivamente, la situación del ciclo gubernamental en curso al momento de sancionarse la constitución, en atención a una eventual implementación de la reelección. De este modo, el artículo 152 de la Ley Fundamental de la Provincia establece la duración de los mandatos del gobernador y del vicegobernador y limita, además, la reelección a una sola etapa gubernamental. Dispone, de este modo, que:

El gobernador y vicegobernador (...) Podrán ser reelectos o sucederse recíprocamente, por un nuevo período únicamente. Si han sido reelectos o se han sucedido recíprocamente, no pueden ser elegidos para ninguno de ambos cargos, sino con intervalo de un período (Const. Pcial. de Sgo. del Estero, 2005, art. 152). 
A su vez, la cláusula transitoria sexta caracteriza al mandato que se encontraba en vigencia en aquel momento como un primer periodo, ante la posibilidad de una continuidad en el Poder Ejecutivo de la administración gobernante, a través del mecanismo de la reelección. Establece, de esta manera, que "el mandato del gobernador de la provincia, en ejercicio al momento de sancionarse esta reforma, deberá ser considerado como primer período (Referida al artículo 152)" (Const. Pcial. de Sgo. del Estero, 2005, cláus. trans. sexta).

La posición del oficialismo santiagueño de aquellos años se enfrentó con marcadas resistencias dentro de la arena política local, lo cual derivó en la canalización institucional de la discusión. Diferentes sectores que integraban el marco opositor cuestionaron judicialmente la postura del Ejecutivo Provincial. Desde un punto de vista técnico jurídico, la diferencia se centró en la determinación de la solvencia constitucional de la cláusula transitoria sexta y, por lo tanto, de la viabilidad de la candidatura consecutiva del gobernador Zamora. En el ámbito jurisdiccional de Santiago la cuestión fue dirimida de forma favorable al Ejecutivo Provincial.

De esta forma, en un pronunciamiento de primera instancia, la cláusula transitoria sexta fue declarada inconstitucional. Esta decisión resultó confirmada por el Superior Tribunal de Justicia, órgano de mayor jerarquía en la estructura judicial de la provincia. Al resolver el asunto, el cuerpo colegiado local, fundó su criterio, entre otros aspectos, en los principios de "irretroactividad" y de "igualdad". Pero, además, teniendo en cuenta que se debatía la constitucionalidad de normas contenidas en una carta política provincial, es decir de reglas procedentes del ejercicio de un poder constituyente, el esfuerzo hermenéutico del Tribunal se enfocó en la exposición de aquellos supuestos y razones que, a su criterio, posibilitaban el cuestionamiento de la salud constitucional de preceptos incluidos en textos constitucionales. Así, entre otros aspectos, el Tribunal les asignó a las cláusulas transitorias un rol instrumental, al caracterizarlas 
como disposiciones destinadas a facilitar la implementación de los cambios que una reforma constitucional supone. Del mismo modo, consideró que la potestad constituyente desplegada en las jurisdicciones provinciales, con sujeción a un procedimiento normado por parte de autoridades embestidas con facultades suficientes, resultaba susceptible de un examen de constitucionalidad. De esta manera, el Tribunal sostuvo que:

Las cláusulas transitorias son "normas" cuyo sentido y finalidad es la de regular o hacer posible la transición de los cambios o las modificaciones operados con motivo de una reforma constitucional (...) El poder constituyente de segundo grado no tiene "poderes ilimitados". Ergo, debe ajustarse a la Constitución y la efectiva vigencia de los derechos fundamentales; Ello implica, que dichas "normas", son pasibles de un control constitucional de razonabilidad y proporcionalidad sobre el contenido de las mismas: los medios arbitrados y sus fines, así como su respeto por los derechos fundamentales (STJ de la Pcia. de Sgo. del Estero, 2013, N 24865).

El "principio de irretroactividad" de las leyes, por su parte, fue vinculado, en la interpretación del Tribunal, con el argumento de la transición entre marcos normativos sucesivos. En efecto, según tal inteligencia, la primera elección del gobernador, en el año 2005, resultaba comprendida dentro del régimen jurídico emergente de la constitución precedente. En cambio, la reelección del año 2009 debía ser entendida como el primer periodo gubernamental al amparo del contexto normativo derivado de la Constitución reformada. De conformidad con tal razonamiento, aquel primer mandato iniciado en el año 2005 se situaba fuera del alcance de la cláusula transitoria sexta, ya que someterlo al imperio de la actual carta política hubiera implicado una vulneración al principio de irretroactividad de la ley. De este modo, el tribunal expresó que:

Esta solución se compadece no sólo con el principio de interpretación favorable al ejercicio de los derechos fundamentales, sino también resulta compatible y armónica 
con el principio de irretroactividad de las normas, que prohíbe proyectar al pasado los efectos que una norma conlleva, lo que sucedería en la especie, de considerar válida la norma transitoria cuestionada, toda vez que la primera elección del actual gobernador ocurrida en el año 2005, fue, indudablemente, un hecho cumplido bajo la vieja Constitución, y que además, resultaba temporalmente incompleto como para considerarlo "primer período"; la segunda, en el año 2009 lo fue al amparo de la nueva, actualmente vigente, por tanto, será este último, el primer mandato a los fines de la aplicación del art. $152^{\circ}$ de la Constitución de la Provincia (STJ de la Pcia. de Sgo. del Estero, 2013, No 24865).

A su vez, el Tribunal interpretó que el contenido de la Cláusula transitoria sexta resentía el "principio de igualdad" al imponerle una restricción, exclusivamente, al gobernador. Para ello, la autoridad judicial efectuó un análisis comparativo del tratamiento conferido por la carta política a otros funcionarios en supuestos semejantes. En el parecer del órgano judicial, la limitación preceptuada en la cláusula transitoria sexta recaía, únicamente, sobre el gobernador, colocándolo en un escenario de desigualdad en comparación con el trato dispensado, por el propio texto constitucional, a otros cuadros electivos. Así, en la sentencia, la colisión entre el contenido de la cláusula bajo análisis y el "principio de igualdad" es abordada, entre otros, en los siguientes términos:

Se advierte que pese a que tanto la consagración de la posibilidad de reelección como la limitación prevista en el art. $152^{\circ}$ de la Constitución de la Provincia alcanzan tanto al gobernador como al vicegobernador de la provincia, sin embargo, y a pesar de encontrarse en la misma situación jurídica, la norma evaluada, sólo se dirige al gobernador en ejercicio, vulnerando de esta manera, el principio de igualdad consagrado por el art. $16^{\circ}$ de la Constitución Nacional $^{15}$ (STJ de la Pcia. de Sgo. del Estero, 2013, No 24865).

15 Este razonamiento es profundizado por el Superior Tribunal al destacar que "la violación al principio de igualdad también se encuentra patentizada en el contenido de la cláusula 
Por lo tanto, la posición del Tribunal frente a la cláusula transitoria en crisis configuraba, a criterio del mismo "la solución que más se ajusta al principio de igualdad, dado que todo sistema constitucional posee condiciones para hacer efectivo su funcionamiento $\mathrm{y}$, tales condiciones, resultan incuestionables, siempre que las limitaciones que imponga no sean arbitrarias o discriminatorias" (STJ de la Pcia. de Sgo. del Estero, 2013, $\mathrm{N}^{\mathrm{o}}$ 24865).

Considerando la decisión del Superior Tribunal de Justicia de la provincia, el interventor del radicalismo en Santiago del Estero sometió la cuestión a conocimiento de la Corte Suprema de Justicia de la Nación. En tal oportunidad la autoridad del radicalismo local promovió acción declarativa en los términos del artículo 322 del Código Procesal Civil y Comercial de la Nación a los efectos de que el máximo órgano judicial del país esclareciera si el gobernador podía competir en la contienda electoral para acceder a un tercer período consecutivo de gobierno (Moltini, 2015). Además, el interventor del partido radical solicitó, por vía cautelar, la suspensión de los comicios para elegir gobernador y vicegobernador (Moltini, 2015). La Corte reconoció que el asunto se inscribía en su jurisdicción originaria y concedió la cautelar peticionada. Al respecto, entendió que:

Cabe también admitir la medida cautelar innovativa requerida, pues si bien este Tribunal ha considerado a ese tipo de solicitudes como una decisión excepcional,

\footnotetext{
transitoria "octava", en la cual -para regular el límite a la posibilidad de ser reelegidos a los miembros integrantes del Tribunal de Cuentas de la Provincia-se dispone que se considerará primer mandato el período 2009-2013 (...) Otra desigualdad de trato, se evidencia en la primera parte de la transitoria "cuarta", en donde se establece un criterio totalmente opuesto que el establecido en la sexta para el mandato del gobernador en ejercicio, con respecto a los diputados que resultaran electos para el período 2007-2009; al igual que para las funciones del vicegobernador (transitoria "quinta") (...) Es decir, el constituyente cuando regula la situación de funcionarios que se encuentran en una misma situación jurídica (en cuanto al cómputo de los mandatos a los fines de la reelección), lo hace -expresamente-de manera diferente ..." (STJ de la Pcia. de Sgo. del Estero, 2013, N 24865).
} 
por configurar un anticipo de jurisdicción favorable respecto del fallo final de la causa que altera el estado de cosas existente (conf. Fallos: 316:1833 y 319:1069), las ha admitido cuando existen fundamentos de hecho y de derecho que exigen una evaluación del peligro de permanencia en la situación a fin de habilitar una resolución que concilie -según el grado de verosimilitud- los intereses en juego. Es de la esencia de estos institutos procesales de orden excepcional enfocar sus proyecciones $\sim$ en tanto dure el litigio- sobre el fondo mismo de la controversia, ya sea para impedir un acto o para llevarlo a cabo, porque dichas medidas se encuentran enderezadas a evitar la producción de situaciones que podrían tornarse de muy dificultosa o imposible reparación en la oportunidad del dictado de la sentencia definitiva (CSJN, 2013a, 336:1756).

Adelantando su posición sobre el fondo del tema principal de autos, la Corte precisó el alcance que debía asignárseles al cuestionado artículo 152 de la carta política santiagueña. De esta forma, razonó:

Cuando el artículo 152 prevé que si el gobernador y el vicegobernador han sido reelectos o se han sucedido recíprocamente, no pueden ser elegidos para ninguno de ambos cargos, sino con intervalo de un período, corresponde únicamente concluir que el pueblo de la provincia -a través de sus constituyentes- estableció el límite de una sola reelección consecutiva para los cargos mencionados. El constituyente provincial consideró además el caso específico del actual gobernador -que promediaba en ese entonces su primer mandato- y completó la regla del artículo 152 con la disposición transitoria sexta, según la cual el mandato del Gobernador de la Provincia, en ejercicio al momento de sancionarse esta reforma, deberá ser considerado como primer periodo (Referida al artículo 152). De ambas normas se deriva sin dificultad interpretativa alguna que la Constitución adoptada por el pueblo de Santiago del Estero en 2005 establece la regla de una sola reelección consecutiva, y aclara específicamente que 
el período 2005-09, en el que el actual gobernador desempeñó ese mismo cargo, debe ser contabilizado como el primer período (CSJN, 2013a, 336:1756).

Debido a que la resolución de la cautelar peticionada anticipaba con claridad el criterio de la Corte en el asunto, el gobierno de Santiago del Estero decidió desistir de su participación en las elecciones. El oficialismo santiagueño propuso, entonces, como candidata a gobernadora, a la esposa del primer mandatario provincial. A pesar de que la modificación suscitada en el cuadro de los acontecimientos tornaba, por ende, abstracto el pronunciamiento judicial pendiente, la Corte decidió, no obstante, pronunciarse sobre el planteo por la relevancia que la cuestión presentaba para la vitalidad de las instituciones republicanas involucradas ${ }^{16}$. De esta manera, la Corte expresó:

El constituyente provincial del año 2005 fue soberano para establecer como primer período a los efectos del artículo 152 al comprendido entre los años 2005 y 2009 y pudo, evidentemente, elegir una solución distinta, pero no lo hizo. En consecuencia, no es constitucionalmente válido que el doctor Zamora se presente como candidato a gobernador para el período 2013-2017 [...] Las cláusulas transitorias tienen por finalidad dar solución a las situaciones concretas que plantea la transición entre el viejo y el nuevo régimen constitucional, para evitar dispares interpretaciones. En el caso de la reelección del gobernador santiagueño, los constituyentes, ante la necesidad de establecer una regla clara y precisa sobre

\footnotetext{
16 En tal sentido la Corte interpreto: "Que la circunstancia de que aquella renuncia haya modificado objetivamente la configuración fáctica que existía en el momento en que se dedujo la acción y que, en consecuencia, haya quedado materialmente satisfecha la pretensión esgrimida por la actora, no torna inoficioso el tratamiento del planteo, ni resta virtualidad al pronunciamiento sobre la cuestión de fondo, ya que se presenta una situación de gravedad institucional que excede el mero interés de los litigantes y afecta de manera directa al de la comunidad (Fallos: 325:3243), desde que se comprometieron instituciones básicas de la Nación (Fallos: 307:973), razón por la cual esta Corte dictó la medida cautelar en tiempo oportuno a fin de preservar el correcto funcionamiento de las instituciones de acuerdo a las leyes que las rigen" (CSJN, 2013b, 336:1756).
} 
cómo debía ser considerado el mandato representativo que a la fecha de la reforma se encontraba ejerciendo el doctor Zamora, optaron por considerarlo como primer período. En estos supuestos se trata de las opciones que han elegido los constituyentes ante la necesidad de establecer con precisión las reglas aplicables a cada situación [...] la forma republicana de gobierno -susceptible, de por sí, de una amplia gama de alternativas justificadas por razones sociales, culturales, institucionales, etc.no exige necesariamente el reconocimiento del derecho de los gobernantes a ser nuevamente electos, y que las normas que limitan la reelección de quienes desempeñan autoridades ejecutivas no vulneran principio alguno de la Constitución Nacional (CSJN, 2013b, 336:1756).

Los fundamentos, expresados por la Corte a través de sus considerandos, surcan una serie de tópicos relevantes directamente vinculados con la cuestión, entre los cuales pueden destacarse los siguientes:

\section{a) Intromisiones en el ámbito de la autonomía provincial}

La Corte resaltó que su decisión de resolver el fondo del asunto no implicaba una interferencia en el funcionamiento institucional del Estado provincial y un avasallamiento de la carta política local, y, por lo tanto, tampoco suponía una vulneración de lo dispuesto por el artículo 5 de la Constitución Nacional. Así, señaló:

Baste indicar que este Tribunal no se ha entrometido [...] sino que ha cumplido con su deber constitucional de asegurar el pleno respeto de la Constitución provincial, a fin de imponer el cumplimiento del compromiso asumido por la demandada en el Artículo $5^{\circ}$ de la Constitución Nacional, que garante a cada provincia el goce y ejercicio de sus instituciones si se rigen por el sistema representativo republicano (CSJN, 2013b, 336:1756).

En el parecer del máximo tribunal nacional, su determinación se encontraba justificada por la situación de gravedad 
institucional que atravesaba la provincia, lo cual despejaba la posibilidad de asociar la decisión judicial con una intervención en la atribución del Estado provincial resultante del artículo 5. En efeto, puesto que "por propia necesidad generada por el mismo Estado provincial" (CSJN, 2013b, 336:1756), los compromisos derivados entre otras normas, del artículo 5 "se pusieron seriamente en riesgo, y sellaron la intervención de la Corte para hacer efectivo su cumplimiento" (CSJN, 2013b, 336:1756). De este modo, en esta línea, el alto tribunal argumentó que:

No debe verse en ello una intromisión indebida de esta Corte, desde que el Tribunal no está ejerciendo una facultad revisora del estatuto provincial, sino que, por el contrario, con su intervención persigue el efectivo cumplimiento de las cláusulas constitucionales que fueron vulneradas (CSJN, 2013b, 336:1756).

Con el propósito de fundamentar el sentido de su accionar en la cuestión en litis, la Corte explicó el sentido que adquiría su intervención a partir de una interpretación del funcionamiento ensamblado de los artículos 1, 5, 116, 122 y 131 de la Constitución Nacional. En la posición de la Corte, la convergencia de aquellos artículos además de consagrar la autonomía política de las provincias, concede e impone a la Corte, al demarcar su ámbito competencial, la elevada misión de asegurar el imperio pleno de la Constitución y la vigencia del sistema federal, aunque ello importe, excepcionalmente, cuestionar el despliegue de aquella autonomía cuando el resguardo del orden institucional y la estabilidad del esquema representativo y republicano, instaurados por la propia Carta Política, así lo requieran. El escenario fáctico, suscitado en Santiago del Estero, con su correspondiente tensión legal e institucional, y que nutría la cuestión que debía dirimirse, configuraba, a criterio del máximo tribunal, una situación institucionalmente riesgosa que contrariaba el formato republicano, representativo y federal y que, por lo tanto, colisionaba con las definiciones rectoras de la Constitución Nacional. De esta manera, la Corte sostuvo que: 
[...] De conformidad con lo dispuesto en el Artículo 122 de la Constitución Nacional las provincias eligen a sus gobernadores sin intervención del Gobierno Federal, con la obvia salvedad de que en este precepto la palabra "Gobierno" incluye a la Corte Suprema. Dicha cláusula se halla dirigida, indudablemente, a prevenir toda injerencia del poder central sobre un asunto de tanta trascendencia política como es, en cuanto aquí interesa, el concerniente a la elección de las máximas autoridades de la Administración provincial. Sin embargo, tal prohibición no debe ser entendida con un alcance absoluto; frente a ella y con igual rango se erige la cláusula que otorga competencia a esta Corte para conocer de todas las causas que versen sobre puntos regidos por la Constitución (Artículo 116) [...] Que la Constitución Nacional que garantiza a las provincias el establecimiento y el ejercicio de sus instituciones, y la elección de sus autoridades, sujeta a ellas y a la Nación al sistema representativo y republicano de gobierno (Artículos $1^{\circ}$ y $5^{\circ}$ ), impone su supremacía sobre las constituciones y leyes locales (Artículo 31) y encomienda a esta Corte el asegurarla como último custodio de la Ley Suprema (Artículo 116). Mas esa intervención está rigurosamente limitada a los casos en que frente a un evidente y ostensible apartamiento del inequívoco sentido que corresponde atribuir nada más ni nada menos que a la Carta Magna, que en el ejercicio pleno de su soberanía se dio el pueblo de Santiago, queden lesionadas instituciones fundamentales de los ordenamientos provinciales que hacen a la esencia del sistema representativo republicano que las provincias se han obligado a asegurar. Solo ante situaciones de excepción como la enunciada, la actuación de ese tribunal federal no avasalla las autonomías provinciales, sino que procura la perfección de su funcionamiento asegurando el acatamiento a aquellos principios superiores que las provincias han acordado respetar al concurrir al establecimiento de la Constitución Nacional (CSJN, 2013b, 336:1756). 


\section{b) La soberanía popular}

La Corte caracterizó a la limitación contenida en la cláusula transitoria como una expresión de la soberanía del pueblo de la provincia de Santiago del Estero. Por la tanto la interpretación forzada, sustentada por el oficialismo santiagueño, comportaba, según la inteligencia del alto tribunal, desconocer esta manifestación concreta de ejercicio soberano y soslayar su profundo significado, en términos legales e institucionales. Así, la Corte entendió que:

[...] En el sistema representativo de gobierno consagrado por el Artículo $1^{\circ}$ de la Constitución Nacional, el pueblo es la fuente originaria de la soberanía (Fallos: 168: 130), y en ese carácter ha decidido ejercerla a través de sus representantes en la oportunidad del dictado de la Ley local $\mathrm{N}^{\circ} 6.736$ que declaró la necesidad de reforma parcial de la Constitución provincial, y en la convocatoria a la Convención que en el año 2005 consagró las cláusulas previstas en el Artículo 152 y en la disposición transitoria sexta que aquí serán objeto de examen (Artículos 22 y 30 Ley Fundamental) [...] Que es preciso señalar que la soberanía popular es un principio de raigambre constitucional que en el sistema democrático se integra con el reconocimiento del pueblo corno último titular del poder político, pero, al mismo tiempo, y para cumplir con tal objetivo, pone su acento en los procedimientos habilitados para hacer explícita aquella voluntad, origen del principio de representación (CSJN, 2013b, 336:1756).

\section{c) La interpretación de la cláusula transitoria}

A través del análisis del alcance de la cláusula transitoria discutida la Corte introdujo algunas pautas de interpretación específicas. Así, se inclinó por defender la literalidad textual de la norma y por respetar el espíritu del constituyente, repudiando cualquier intento del juzgador de modificar, confrontar o desconocer aquella voluntad del legislador plasmada en el 
dispositivo transitorio. De esta manera, la Corte, remitiéndose a un criterio ya invocado con anterioridad, afirmó que:

Cabe recordar la inveterada jurisprudencia del Tribunal en el sentido de que, en materia interpretativa, 'la primera regla consiste en respetar la voluntad del legislador y, en tal sentido, cabe estar a las palabras que ha utilizado. Si la ley emplea determinados términos la regla de interpretación más segura es la que esos términos no son superfluos, sino que han sido empleados con algún propósito, por cuanto, en definitiva, la misión de los jueces es dar pleno efecto a las normas vigentes sin sustituir al legislador ni juzgar sobre el mero acierto o conveniencia de disposiciones adoptadas por aquél en el ejercicio de facultades propias' [Fallos: 318:1012, considerando $3^{\circ} \mathrm{y}$ sus citas] (CSJN, 2013b, 336:1756).

Asimismo, la Corte, luego de desatacar el significado incuestionable de la letra de la norma transitoria ${ }^{17}$, y remitiéndose a un precedente de la Corte Interamericana de Derechos Humanos, descartó cualquier tipo de interpretación del contenido de dicha cláusula bajo estudio, que pudiera conducir a su calificación como disposición restrictiva con respecto al disfrute y ejercicio de los derechos políticos, de conformidad con lo prescripto por el artículo 23 de la Convención Americana sobre Derechos Humanos ${ }^{18}$. En tal sentido, la Corte puntualizó que:

17 En tal dirección el alto tribunal nacional señaló que "el significado de la cláusula transitoria transcripta, interpretada literalmente y en el sentido más obvio del entendimiento común (Fallos: 258:75, entre otros), es de una precisión y claridad incontrastables. En ella se alude sin duda al doctor Gerardo Zamora, porque era él el gobernador en ejercicio al momento de sancionarse la reforma constitucional que la introdujo, quien había asumido el cargo el 23 de marzo de 2005 por un período de cuatro años en los términos de la Constitución provincial de 1997. Luego el doctor Zamora fue reelecto gobernador para el período 2009/2013, el que comenzó el 10 de diciembre de 2009" (CSJN, 2013b, 336:1756).

18 El citado precepto de la convención multilateral del ámbito continental que: "1. Todos los ciudadanos deben gozar de los siguientes derechos y oportunidades: a) de participar en la dirección de los asuntos públicos, directamente o por medio de representantes libremente elegidos; b) de votar y ser elegidos en elecciones periódicas auténticas, realizadas por sufragio universal e igual y por voto secreto que garantice la libre expresión de la voluntad 
[...] La previsión contenida en la cláusula transitoria examinada tampoco resulta violatoria de las disposiciones del Artículo 23 de la Convención Americana sobre Derechos Humanos pues el establecimiento y aplicación de requisitos para ejercitar los derechos politicos no constituyen, per se, una restricción indebida ya que esos derechos no son absolutos y pueden estar sujetos a limitaciones (conf. Corte Interamericana de Derechos Humanos, Caso Yatama vs. Nicaragua, sentencia del 23 de junio de 2005). En razón de ello, se admite la validez de su reglamentación en la medida en que ésta observe los principios de legalidad, necesidad y proporcionalidad en una sociedad democrática [Corte Interamericana, fallo cit.] (CSJN, 2013b, 336:1756).

\section{d) La gravedad institucional y su impacto en el esquema republicano y representativo}

A partir de la ponderación de las eventuales repercusiones institucionales que podía generar, en caso de ser admitida, la interpretación oficialista de la cláusula transitoria, la Corte enfocó la cuestión problemática considerando la salud misma del sistema representativo y republicano. Ciertamente, desde tal perspectiva, la Corte subrayó la relevancia institucional que la situación presentaba, la cual superaba los concretos intereses de los protagonistas electorales. Así, en el pronunciamiento se enfatiza en:

[...] La gravedad institucional que reviste el caso excede el mero interés individual del gobernador provincial y atañe al de la comunidad, desde que están en juego instituciones básicas de la Nación, que la provincia se encuentra obligada a resguardar [...] Frente a la

de los electores, y c) de tener acceso, en condiciones generales de igualdad, a las funciones públicas de su país. 2. La ley puede reglamentar el ejercicio de los derechos y oportunidades a que se refiere el inciso anterior, exclusivamente por razones de edad, nacionalidad, residencia, idioma, instrucción, capacidad civil o mental, o condena, por juez competente, en proceso penal" (Convención Americana sobre derechos Humanos, artículo 23). 
incompatibilidad que se presentaba en el caso entre los intereses individuales del doctor Zamora y los de la provincia, entendidos como la consagración real de los compromisos asumidos en el certero condicionamiento impuesto por el Artículo 5' de la Ley Fundamental, los que deben tener efectividad y realización ciertas, debieron primar estos últimos (CSJN, 2013b, 336:1756).

Con una actitud crítica hacia la decisión adoptada por la justicia provincial, la Corte le atribuye su cuota de responsabilidad a la posición esgrimida, en el asunto discutido, por las autoridades judiciales, en la conformación del panorama de gravedad institucional. En esta línea, el alto tribunal puntualizó:

[...] Cabe recordar que es la provincia la que se encuentra obligada a honrar el sistema representativo y republicano de gobierno, y al acatamiento de aquellos principios que todos en conjunto acordaron respetar al concurrir a la sanción de la Constitución Nacional (Artículos $1^{\circ}$ y $5^{\circ}$; Fallos: 310:804) [...] El exceso en sus facultades en que ha incurrido la jurisdicción provincial al declarar la inconstitucionalidad de la referida disposición transitoria resulta evidente, ya que mediante el pronunciamiento emitido se pretende suplir la voluntad del constituyente expresada claramente en esa cláusula. Es imposible concebir un Poder Constituido que pueda, por designio e inercia, dejar sin efecto lo preceptuado por el Poder Constituyente [Fallos: 242: 112] (CSJN, 2013b, 336:1756).

\section{A Modo de Cierre}

Cómo pudo apreciarse el sistema electoral de la provincia de Santiago del Estero guarda marcadas semejanzas, desde una perspectiva técnica, con los regímenes electorales de otras provincias. Teniendo en cuenta la incursión realizada en los aparatados precedentes, se pueden expresar una serie de consideraciones: 
- El marco normativo del sistema electoral vigente surge de la Constitución provincial en su versión del año 2005 y de la ley 6908 del año 2008, con sus posteriores modificaciones, que instaura el código electoral de la provincia. Los aspectos principales del sistema que se encuentran normados en la ley citada y sus ulteriores enmiendas reconocen una previa consagración en la letra constitucional. Así, entre otros tópicos, lo atinente a la duración de los mandatos de los cargos electivos de mayor relevancia, tanto de la órbita del poder ejecutivo como del órgano legislativo; la renovación de los mismos; el plazo para la convocatoria a elecciones; el mecanismo de elección; y las pautas que ordenan la reelección, se hallan insertos en la referida carta política.

- Tanto la reforma de la constitución provincial como la citada ley fueron promovidas por la conducción gobernante por entonces. En consecuencia, puede decirse que la configuración del sistema electoral vigente respondió al impulso oficialista de aquella instancia. La intervención federal, indudablemente, había procurado, en su momento, actualizar el sistema electoral, y modificar, así, el régimen en la materia, que se remontaba al ciclo juarista. De tal propósito dan cuenta la tentativa de la provisoria administración federal de modificar la carta política de la provincia y el ejercicio de la potestad normativa en cuestiones referentes a la actividad electoral, como lo son el financiamiento de los partidos políticos, la consulta popular, el acceso de las agrupaciones políticas a los medios de comunicación, y el voto electrónico.

- El sistema electoral procuró ordenar las distintas manifestaciones del espectro electoral mediante una serie de criterios rectores. Así, se unificó en cuatro años la duración de los mandatos de los cargos electivos, tanto en la esfera de la autoridad ejecutiva como del órgano judicial, a través de los diferentes niveles de desagregación de la administración estatal, es decir provincial y municipal. En consonancia con ello, también se estableció la simultaneidad de las elecciones con el propósito 
de asegurar una concordancia en el proceso de renovación de los cargos electivos de los poderes ejecutivo y legislativo. Del mismo modo, a los efectos electorales, el territorio provincial, en su totalidad, es considerado, a partir de entonces, un distrito único.

- Al admitir la medida cautelar dirigida a suspender los comicios gubernamentales, incluyendo la cuestión en el perímetro de su jurisdicción originaria, la Corte Suprema identificó la existencia de un grave riesgo institucional ante el supuesto de una eventual prosecución del estado de cosas, el cual podía tornarse insalvable o, en su caso, de compleja reparación, al momento del pronunciamiento definitivo. Por ende, el cuadro de situación que configuraba un escenario de grave riesgo institucional se encontraba definido, a criterio de la Corte, en primer lugar, por la posibilidad de una reelección gubernamental sustentada en una interpretación severamente cuestionable de una cláusula transitoria de la de la carta política dotada de un sentido específico; y, en segundo lugar, por la conformidad judicial con respecto a la probabilidad de modificar la validez y/o los efectos jurídicos de los dispositivos constitucionales a través de un fallo de un juez de jerarquía inferior, lo cual implicaba admitir la factibilidad de declarar la inconstitucionalidad de los propios contenidos de la Constitución por un órgano diferente a aquel que, en su momento, intervino en la sanción o reforma del texto constitucional, y mediante un procedimiento no previsto en la propia Constitución.

- La controversia generada en torno a la viabilidad de la reelección en los comicios del año 2013 trasladó las tensiones de la palestra política hacia el ámbito institucional. El conflicto reveló el propósito del oficialismo provincial de imponer, en pos de la satisfacción de intereses políticos, una interpretación forzada de la cláusula transitoria, la cual establecía un valladar a toda pretensión del gobierno de turno de acceder a un tercer período consecutivo. Tal posición suponía, en definitiva, supeditar la regularidad y estabilidad que debe caracterizar a 
un sistema electoral a los vaivenes propios de los contingentes ritmos políticos. No obstante, es destacable el proceder de algunos actores que, por entonces, integraban el marco opositor al decidir "institucionalizar" la discrepancia y acudir a los mecanismos judiciales para dirimir las diferencias originadas en esta cuestión. Tal cual pudo analizarse, el criterio de la Corte Suprema de la Justicia de la Nación, al resolver este asunto, contenía, implícitamente, la ponderación sobre la necesidad de garantizar la observancia de la letra constitucional y asegurar la consistencia del régimen electoral.

La "institucionalización" de la resistencia por parte de determinados actores del abanico opositor frente a la posición del oficialismo gobernante, no es algo que deba soslayarse, habida cuenta de que, durante las últimas décadas, la cultura política de un amplio sector de la sociedad santiagueña se conformó en un escenario caracterizado por marcados liderazgos personalistas. 